\title{
An inhibitor-interaction intermediate of HIV-1 protease, revealed by Isothermal Titration Calorimetry and NMR spectroscopy
}

Shahid N Khan ${ }^{1 \neq}$, John D Persons ${ }^{1 \neq}$, Michel Guerrero ${ }^{1}$, Tatiana V. Ilina ${ }^{1}$, Masayuki Oda ${ }^{2}$, Rieko Ishima $^{1^{*}}$

${ }^{1}$ Department of Structural Biology, University of Pittsburgh School of Medicine, Pittsburgh, PA, USA

${ }^{2}$ Graduate School of Life and Environmental Sciences ${ }^{3}$, Kyoto Prefectural University, Kyoto, Japan

‡ These authors contributed equally.

*Corresponding Author: Rieko Ishima, Room 1037, Biomedical Science Tower 3, 3501 Fifth Avenue, Pittsburgh, PA 15260. Tel: 412-648-9056. Fax: 412-648-9008. Email: ishima@pitt.edu

Keywords: NMR, calorimetry, HIV-1, Protease, Inhibitor, thermodynamics, ITC

Running title: Inhibitor-interaction with HIV-1 protease mutants 


\section{Abstract}

Some of drug-resistant mutants of HIV-1 protease (PR), such as a clinically-relevant drugresistant PR mutant $\left(\right.$ Flap+(154V) $\left._{(15}\right)$ containing L10I, G48V, 154V and V82A mutations, produce significant changes in the balance between entropy and enthalpy of the drug-PR interactions, compared to the wild-type (WT) PR. Here, to gain a comprehensive understanding of the entropy-enthalpy compensation effects, we compared nuclear magnetic resonance (NMR), fluorescence spectroscopy and isothermal titration calorimetry (ITC) data of a WT PR with Flap $_{(154 \mathrm{~V})}$ and related mutants: (1) Flap $_{(154 \mathrm{~V})}$; (2) $\mathrm{Flap}_{{ }_{(154 \mathrm{~A})}}$ which evolves from Flap $+_{(154 \mathrm{~V})}$ in the continued presence of inhibitor yet does not exhibit entropy-enthalpy compensation; and (3) $\mathrm{Flap}_{(154)}$, a control mutant that contains only L10I, G48V and V82A mutations. Our data indicate that WT and Flap+(154A) show enthalpy-driven inhibitor-interaction, while Flap+(154) and Flap+(154V) exhibit entropy-driven inhibitor interaction. Interestingly, Flap+(154A) exhibited significantly slower heat flow in the competitive ITC experiment with a strong binder, darunavir, and a weak binder, acetyl-pepstatin, but did not exhibit such slow heat flow in the direct inhibitor-titration experiments. NMR confirmed replacement of the weak binder by the strong binder in a competitive manner. This difference in the heat flow of the competitive binding experiment compared to the direct experiment can only be explained by assuming an inhibitor-bound intermediate pathway. A similar, but attenuated, tendency for slow heat flow was also detected in the competitive experiment with WT. Overall, our data suggests that an inhibitor-bound intermediate affects the entropy-enthalpy compensation of inhibitor-PR interaction. 


\section{Introduction}

Human immunodeficiency virus-1 (HIV-1) protease (PR) is an enzyme essential for HIV-1 replication [1-5]. Although structure-based drug design has resulted in the development of various PR inhibitors, the long-term effectiveness of the inhibitors is hampered by generation of drug-resistance mutations [6-20]. To understand the mechanism of the drug-resistance, thermodynamics studies of inhibitor interactions with PR and various drug-resistant mutants have been conducted for the past two decades [21-33]. However, since the PR concentration range typically used in structure studies is much higher than that required for thermodynamics studies, direct comparison of the findings from these two approaches has been hampered. This gap has hindered identification of the protein states responsible for observations made in thermodynamics studies of inhibitor interactions. As a result, modeling of the mechanism of inhibition has been limited.

Our particular interest is Flap+(154V), which contains a set of clinically-relevant drugresistant PR mutations, L10I, G48V, I54V and V82A (Fig. 1). Thermodynamically, inhibitor interactions, such as saquinavir, amprenavir and darunavir (DRV), with Flap+(154v) are known to exhibit entropy-enthalpy compensation compared to WT PR: previous isothermal titration calorimetry (ITC) experiments demonstrated that inhibitor-WT interaction was enthalpy driven while inhibitor-Flap+(154V) was entropy driven [31]. Thus, Flap+(154V) mutations can silently affect the thermodynamics of drug-PR interactions by changing the entropy and enthalpy balance while not significantly changing the total free energy itself. Interestingly, under drug pressures,

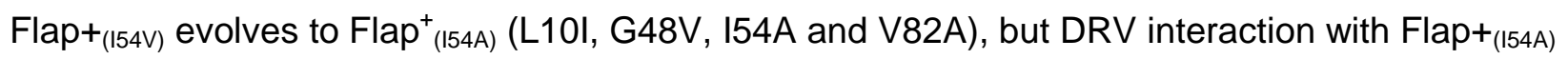
does not exhibit the entropy-enthalpy compensation observed for Flap+(154v) [32]. Furthermore, the individual mutations, 154V, I54A or G48V, do not show entropy-enthalpy compensation [32]. These observations have indicated that simple addition of each individual mutation effect cannot explain the thermodynamic changes observed for Flap+ mutants [32]. Such cooperativity of the 
mutations on the inhibitor-binding thermodynamics was also reported for other, similar PR drugresistance mutants [34].

The structure of HIV-1 PR has been well characterized (Fig. 1): it is a dimer, with the two subunits interfacing via residues in the flaps (residue 45 - 55), the active-site fireman's grip (residues 25 to 27) and the N- and C-terminal $\beta$-sheet [35-37]. They also indirectly interact with each other through inhibitors at the P1 loop, that include one of the Flap mutation sites, residue 82 (Fig. 1). The flaps of HIV-1 PR are known to undergo multiple conformations [38-45]. Previous crystallography, NMR, and MD simulations have shown that Flap+(154v) exhibits significant fluctuation in the flap region $(>0.8 \AA \mathrm{C} \alpha \mathrm{rmsd})$, with more opened flaps in the Flap+(154V) $_{(15}$ compared to WT $[31 ; 46 ; 47]$, suggesting that two possible apo-forms, i.e., open and closed forms, may contribute to the inhibitor-interaction. Computational and experimental studies have proposed the existence of a PR folding intermediate [48], intermediate-inhibitor bound forms [49], and dimer dissociation as a mechanism of inhibition by DRV [50; 51], which may involve changes of other dimer interface structures. Despite the evidence for multiple conformational states being involved in PR-inhibitor interaction, the thermodynamics of inhibitorPR interactions have been analyzed assuming only free and bound states.

Recent development in NMR sensitivity have permitted NMR spectra to be recorded for protein samples at low protein concentrations [52], similar to those used for ITC and fluorescence experiments. Taking advantage of this development, we report our ITC, NMR and fluorescence spectroscopy data of PRs, which were recorded at similar conditions, to understand the molecular mechanism underlying PR-inhibitor interaction. We also introduce an artificial mutant, Flap+(154), which contains mutations L10I, G48V and V82A, and revisit the thermodynamics of inhibitor interaction with $\mathrm{Flap}_{\left({ }_{(154)}\right.}$, Flap+(154V) and $\mathrm{Flap}+_{(154 \mathrm{~A})}$, as well as that 
with a pseudo WT (pWT) ${ }^{1}$ protein that is a backbone of the Flap+ mutants (see details in the Materials and Methods), to identify the underlying mechanism of the entropy-enthalpy compensation. We present (i) the thermodynamics parameters for a weak substrate-analogue inhibitor, acetyl-pepstatin (pepstatin), (ii) the apparent thermodynamics parameters of a strong binder, DRV, in the presence of the weak binder, and (iii) the derived thermodynamics parameters of DRV binding. Both pepstatin and DRV, as a weak and a strong binder respectively, have been used to characterize binding thermodynamics of inhibitor-PR interaction in previous studies $[22 ; 26 ; 27 ; 31 ; 32 ; 53 ; 54]$. To identify the states involved in the PR-inhibitor interaction thermodynamics, we compare Nuclear Magnetic Resonance (NMR) spectra and Trp intrinsic fluorescence emission, at PR concentrations similar to or below those used for ITC. In the end, based on these seamless experiments of both NMR and ITC, we propose that an additional intermediate, possibly an inhibitor-bound dimer intermediate, is needed to explain the data.

\section{Results}

\section{Pepstatin interaction with PRs monitored by ITC}

Pepstatin is an aspartic protease inhibitor and has been used to characterize inhibitor-PR interactions $[22 ; 26 ; 27 ; 31 ; 32 ; 53-55]$. We first characterized the thermodynamics parameters of PR interactions with a weak binder, pepstatin, to utilize the parameters for competitive ITC experiments below and to elucidate inhibitor-interaction characteristics of Flap+ mutants against WT. ITC data of pepstatin with pWT and Flap+ mutants were recorded using similar protein concentrations, $20-30 \mu \mathrm{M}$. Isotherms of pWT and Flap+(154A) were similar to each other while

\footnotetext{
${ }^{1}$ Abbreviations: pWT, a pseudo wild-type PR containing Q7K, L33I, L63P, C67A, C95A mutations: Flap ${ }_{(154 \mathrm{~V})}$, a PR containing L10I, G48V, I54V and V82A mutations on the pWT PR backbone; Flap ${ }_{(154 \mathrm{~A})}$, a PR containing L10I, G48V, I54A and V82A mutations on the pWT PR backbone; Flap ${ }_{(154)}$, a PR containing L10I, G48V and V82A mutations on the pWT PR backbone; pepstatin, acetyl-pepstatin; DRV, darunavir.
} 
isotherms of Flap+(154) and Flap+(154V) were similar to each other (Fig. 2a-h). Thermodynamics parameters of pepstatin binding to pWT at $20{ }^{\circ} \mathrm{C}(\Delta \mathrm{G},-8.72 \pm 0.14 \mathrm{kcal} / \mathrm{mol} ; \Delta \mathrm{H}, 8.7 \pm 0.24$ $\mathrm{kcal} / \mathrm{mol} ;-\mathrm{T} \Delta \mathrm{S},-17.4 \pm 0.28 \mathrm{kcal} / \mathrm{mol}$ ) were consistent with those obtained at $25^{\circ} \mathrm{C}$ by Freire's group $(\Delta G,-8.4 \pm 0.9 \mathrm{kcal} / \mathrm{mol} ; \Delta H, 10.1 \pm 0.7 \mathrm{kcal} / \mathrm{mol},-T \Delta S,-18.4 \pm 0.06 \mathrm{kcal} / \mathrm{mol})$ [21] (Fig. 2a and 2e, and Table 1.1). Thermodynamics parameters of Flap+(154A) were similar to those of pWT while ${\text { Flap }+_{(154)} \text { and Flap+(154v) }}$ exhibited less favorable $\Delta G$ and more unfavorable $\Delta H$, compared to pWT and Flap+(I54A) $($ Fig. 3a-c and Table 1.1).

\section{DRV interaction with PRs monitored by ITC}

Titration of PRs with a strong binder, DRV, was done in the presence of a weak binder, pepstatin (Fig. 2i-2p and Table 1.2). Ideally, the optimal weak binder for competitive ITC experiments would be chosen from a panel of weak binders based on the $K_{D}$ of the strong binder under study [56]. We used a single weak binder, pepstatin, for all PR-DRV interaction studies, to avoid any biases caused by differences in the solubility of weak inhibitors in aqueous solution or differences in the mechanisms of PR interactions of the weak inhibitors. As a result, throughout all DRV-PR interactions, the accuracy of the determined $\Delta G$ and $-T \Delta S$ may be less for DRV that shows a steep apparent titration profile. However, $\Delta H$ is still accurately determined based on the theoretical equation [56]. In the competitive experiments, all the DRV titrations in the presence of pepstatin showed apparent favorable $\Delta H$ changes, which is in contrast to the pepstatin titration (Fig. 2i-2p and Table 1.2) but consistent with previous results [32]. As expected, the molar heat changes were steep in the DRV titration for pWT (Fig. 2m), indicative that practical $\Delta G$ accuracy is lower for these proteins.

Using $\Delta H$ and $\Delta G$ for the pepstatin titration alone and those of the competitive data (Table 1.1 and 1.2), we calculated the thermodynamics parameters of DRV binding to PRs (Table 1.3). Favorable $\Delta H$ was obtained for pWT and Flap+(154A) while near unfavorable (near 
zero or positive) $\Delta H$ values were obtained for Flap+(154) $_{(15)}$ and Flap+(154V), respectively (Table 1.3).

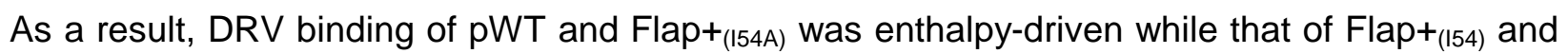

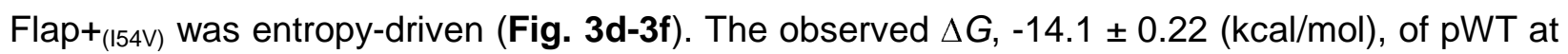
$\mathrm{pH}$ 5.8, which is a condition that slows down autoproteolysis and suitable for a long-term experiments, is slightly higher than that published previously, $-15.0 \pm 0.3(\mathrm{kcal} / \mathrm{mol})$, at $\mathrm{pH} 5.0$ [32]. This may be primarily due to inaccuracy of our experimental condition to detect such low $\Delta G$ binding or secondary because of higher $\mathrm{pH}$ in which Asp hydroxyl protonation at the active site may affect to the DRV interaction. Otherwise, thermodynamics parameters of Flap+(154A) and Flap+(154V) $_{(1)}$ were similar to those published previously [32].

To reveal the mechanism underlying DRV-pepstatin competition in our experiments, the heat flow of each injection was compared. Since the relative bound fractions at each time point differs among the proteins, both the $3^{\text {rd }}$ and $5^{\text {th }}$ injections were assessed (which corresponds to the $\sim 7$ min and $\sim 12$ min points in Fig. $\mathbf{4 a}$ and $\mathbf{4 b}$, respectively). Interestingly, Flap+(154A) heat flow was quite different from the others. pWT also shows a slightly slower heat flow compared to Flap $_{(154)}$ and Flap+(154V). Importantly, such slow heat flow was not observed (Fig. 4a and 4b, green dashed line) in the direct DRV (Fig. 4c) or pepstatin (Fig. 2b) titration of Flap+(154A). Taken together, the thermodynamics changes of inhibitor binding to Flap+(154A) and pWT are similar to

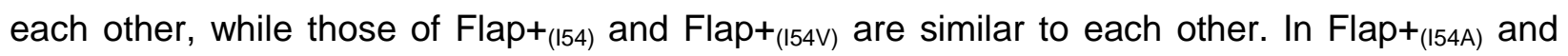
pWT, the competitive experiments are not simply explained by an on and off model of strong and weak binders to PR.

\section{PR dimer dissociation and folding stability}

To understand what states are involved in these PR interactions in solution, we next characterized folding and dimerization of the proteins using intrinsic Trp fluorescence spectroscopy at different protein concentrations and denaturant. Since one of the two Trp residues in $\mathrm{PR}$, residue 6, is located at the dimer interface and exposed to solution upon dimer 
dissociation [57; 58], the fluorescence emission of this residue is known to be reduced by dimer dissociation [48]. In pWT and Flap+ mutants, intrinsic Trp fluorescence spectroscopy exhibited linear protein concentration dependence above $0.25 \mu \mathrm{M}$ (Fig. 5a). Through this analysis, dimer dissociation constants of both pWT and Flap+ mutants were determined to be $<0.25 \mu \mathrm{M}$, which is consistent with previous results obtained for PR and other mutants [59] and confirms that the PRs used in our ITC experiments were dimers. Since the reduction of fluorescence emission is lower in Flap+(154A) compared to $\mathrm{pWT}, \mathrm{Flap}_{{ }_{(154)}}$ and Flap+(154V), the N-terminal region of Flap+(154A), where Trp 6 is located, may be more mobile or experience greater monomer unfolding compared to the other proteins.

Consistent with this notion, urea denaturation produced overall similar profiles among pWT and Flap mutants (Fig. 5b). A slightly lower chemical stability was observed only for Flap $_{(154 \mathrm{~A})}$, with a half urea denaturation concentration at $1.8 \pm 0.1 \mathrm{M}$, compared to the others (2.3 - 2.5 M, respectively) (Fig. 5b). In addition, the fluorescence intensity of Flap $_{(154 \mathrm{~A})}$ in the absence of urea was $10-20 \%$ lower than that of the others, suggesting the presence of an unfolded component or a slightly different conformation of Flap+(154A) compared to the other PR proteins.

\section{NMR probed PR conformation.}

PR structural changes that are involved in the inhibitor-PR interaction observed by ITC were also characterized by recording NMR spectra at different protein concentrations and in the presence and absence of inhibitors. We firstly recorded NMR spectra at a protein concentration lower than those used for ITC, $3 \mu \mathrm{M}$, to establish proper folding of the PRs. NMR spectral patterns of pWT and Flap+(154V) were essentially similar to those published previously, both in apo (Fig. 5c) and DRV-bound forms (Fig. 5d) [60]. Flap+(154) spectra also exhibited very similar resonance patterns to those of Flap+(154V) $_{(1)}$ both forms (Fig. 5c and 5d). Only the NMR spectrum of Flap+(154A) showed a significant unfolded fraction, $29 \%$ and $17 \%$ in the apo and 
DRV-bound forms, respectively, estimated from the signal intensity of indole $\mathrm{NH}$ resonances (Fig. 5c and 5d). These observations of the apo-dimer forms of pWT and Flap+ mutants are consistent with the protein concentration dependence of Trp fluorescence (Fig. 5a). Similarly, observation of the unfolded component of Flap+(154A) is consistent with the lower intensity of Trp fluorescence in this mutant compared to the other mutants (Fig. 5b).

Since Flap+(154A) exhibited NMR spectral feature that contains unfolded fraction, we further characterized how the unfolded fraction changes at $40 \mu \mathrm{M}$ protein concentration, which is similar to that used for the ITC experiments. The apo form of $\mathrm{Flap}_{\left({ }_{(154 A)}\right.}$ exhibited a similar spectral feature to that at $3 \mu \mathrm{M}$ (Fig. 5e, black). Addition of pepstatin to the $-\mathrm{Flap}_{(154 \mathrm{~A})}$, after recording the apo spectrum, changed the spectral pattern, presumably from that of the apodimer form to that of the pepstatin-bound form (Fig. 5e, red). Upon further addition of DRV to the Flap+(154A) solution containing pepstatin, the spectral pattern indicated changes from the pepstatin-bound form to the DRV-bound form (Fig. 5f, green). Importantly, the unfolded fraction in the Flap+$_{(154 \mathrm{~A})}$, approximately $20 \%$, was not changed upon addition of pepstatin, or further addition of DRV, that mimicked the order of inhibitor competition in the ITC experiments (Table 2). Even when DRV was directly added to the folded apo-Flap+(I54A), containing $20 \%$ unfolded fraction, the unfolded fraction was neither decreased or increased (Table 2 and Fig. S1a). Only when the protein was folded in the presence of inhibitor did the population of the unfolded fraction became small, $5-8 \%$, indicating that the inhibitors facilitate folding of the protein (Table 2 and Fig. S1b). These NMR resonance patterns of Flap+ ${ }_{(154 A)}$ in the presence of DRV are very similar to that of $\mathrm{Flap}_{\left({ }_{(154)}\right.}$ which differs by only one residue from Flap+(154A) $($ Fig. S1C). These observations suggest that the unfolded fraction in the apo-form of Flap+(154A) is a misfolded component or fragments caused by autoproteolysis (Fig. S2), and does not participate in the inhibitor interaction throughout the experiments (Table 2). 


\section{Discussion}

In this study, we aimed to understand the molecular mechanism underlying PR-inhibitor interaction, using ITC, NMR and fluorescence spectroscopy. Side-by-side NMR and ITC experiments elucidated the states involved in the thermodynamics changes upon inhibitor-PR interaction. Using this approach, we have made the following overall observations: First, the proteins are folded as a dimer at $>\mu \mathrm{M}$ concentration. Second, $\Delta H$ of inhibitor interaction with pWT and Flap+(154A) was more favorable than that of $\mathrm{Flap}_{{ }_{(154)}}$ and $\mathrm{Flap}_{(154 \mathrm{~V})}$, in both DRV and pepstatin interactions. In contrast, $-T \Delta S$ of $\mathrm{Flap}_{(154)}$ and $\mathrm{Flap}+_{(154 \mathrm{~V})}$ was more favorable than that of pWT and Flap+(154A). These observations suggest that evolution from I54V to I54A likely makes the inhibitor-binding thermodynamics of the Flap+ mutant more similar to that of pWT.

Differences in the thermodynamics of the inhibitor interactions with the various PR proteins suggest a previously unrecognized inhibitor-bound intermediate. Specifically, a slow

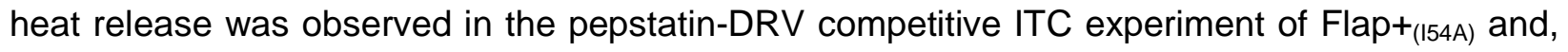
less so, of pWT (Fig. 4a and 4b). Importantly, such a slow release was not detected in the direct DRV or pepstatin titration experiments (Fig. $\mathbf{2 a}, \mathbf{2 b}, \mathbf{4 a}$ and $\mathbf{4 b}$ ). Since the NMR spectra demonstrated that Flap $_{(154 \mathrm{~A})}$ binds to pepstatin, which is subsequently replaced by DRV (Fig. 5e and $\mathbf{5 f}$ ), the slow process is not due to differences in inhibitor-on/off rates of the proteins or unfolding of the protein, but is due to an intermediate process. If the intermediate is between the apo and inhibitor-bound states, competitive titration would not show such a difference in heat flow, compared to the direct titration, because DRV binds the apo-form in the equilibrium between the apo and pepstatin-bound forms. Thus, we conclude that the intermediate exists but is not located on the PR folding pathway (Fig. 6a) and is, instead, located at a step that produces a difference between the direct-titration and competitive titration, i.e, on another inhibitor binding pathway (Fig. 6b). 
Based on these observations, we postulate a model that contains an inhibitor-bound intermediate state (state (II) in Fig. 6b) in addition to the direct apo-bound pathway (state (I) to (III) in Fig. 6b). To place the inhibitor-bound intermediate (II) in the scheme, two states or two different conformers within a state of the apo homodimer, $\left(I_{a}\right)$ and $\left(I_{b}\right)$, are assumed (discussed below). The model in Fig. $6 \mathbf{b}$ explains the heat flow in the competitive titration of $\mathrm{Flap}_{(154 \mathrm{~A})}$, and possibly pWT, as follows. In the direct inhibitor-PR titration, PR undergoes either pathway (I)(III) or (I)-(II)-(III), or both, depending on the mutations. In the competitive ITC experiment, in which PR is filled by a weak binder in state (III), a strong binder binds the low-populated apo form in state $\left(I_{b}\right)$ and shifts the equilibrium to the strong binder bound form in state (III), in which the direct pathway is $\left(I_{b}\right)-(I I I)$. Thus, when $\left(I_{b}\right)-(I I I)$ is the major pathway of the direct inhibitor interaction, the competitive experiment will show a heat flow similar to that of the direct interaction. On the other hand, when $\left(\mathrm{I}_{\mathrm{a}}\right)-(\mathrm{II})-(\mathrm{III})$ is the major pathway of the direct inhibitor interaction, competitive binding of DRV may occur via the (III)-(II)-( $\left.\mathrm{I}_{\mathrm{a}}\right)$ pathway (backwards). However, a population that goes through the (III) - $\left(I_{b}\right)$ pathway (reversed) may also become evident because most of the PR is in the (III) state. In this case, heat flow in the competitive experiments may be different from that of the direct binding experiments, such as observed for $\mathrm{Flap}_{(154 \mathrm{~A})}$.

Thermodynamically, we observed that inhibitor interactions of Flap+(154A) and pWT are $\Delta H$ driven while inhibitor interactions of $\mathrm{Flap}_{\left({ }_{(154)}\right.}$ and Flap+$+_{(154 \mathrm{~V})}$ are $-T \Delta S$ driven (Table 1.3). In the above two-pathway model (Fig. 6b), this difference in thermodynamics characteristics may indicate that the inhibitor-bound intermediate path, (I)-(II)-(III), is $\Delta H$ driven while the direct binding path, (I)-(III), is $-T \Delta S$ driven. In this case, the intermediate path may involve more protein conformational change $(\Delta H$ driven), while the direct binding path involves burial of hydrophobic inhibitor to the rigid homodimer (-TAS driven).

Structurally, two slightly different dimer forms may exist, as discussed below. Previous studies showed a more open flap conformation in Flap+(154V) compared to pWT in the apo form 
[46; 47] and showed that Flap+(154V) exhibits a slightly different conformation, on average less than $1 \AA$, from the pWT in the DRV bound form $[31 ; 46 ; 47]$ [60]. Thus, the simplest scenario for the two forms in state $(I)$ of our model may be closed- $\left(I_{a}\right)$ and open- $\left(I_{b}\right)$ flap forms: when the flaps are more closed, inhibitor binding will need a PR conformational change, which may involve significant enthalpy changes. Another scenario of the two forms in state (I) may instead involve a folding intermediate: the Flap mutations are not simply additive of effects of individual mutation; all four mutations span the direct and indirect dimer interfaces (Fig. 1); Flap+(154A) and pWT showed weaker chemical denaturation compared to Flap+(154) and Flap+(154V). The latter model may be valid considering the proposed existence of a PR folding intermediate [48], intermediate-inhibitor bound forms [49], and DRV as a dimer dissociation inhibitor [50; 51]. The two subunits of the PR dimer have multiple direct subunit interaction sites, including the flap region, active-site fireman's grip (residues 25 to 27), and the $\mathrm{N}$ - and C-terminal $\beta$-sheet (Fig. 1) [35-37]. Indeed, another set of mutations, L10I/ M46I/I54V/V82A/I84V/L90M, that spans both the direct and indirect dimer interfaces, but not a mutant with only the M46I//54V mutations, also shows the entropy-enthalpy compensation [34]. Although the exact conformation of the intermediate and the binding pathway model is not identified from the current study, our results indicate that an inhibitor-bound intermediate exists in the pWT and Flap+(154A). Since PR recognizes nine different natural substrates in the Gag-Pol polyproteins [61], it may need flexibility in molecular recognition, i.e., having both a $\Delta H$ favored intermediate path and a $-T \Delta S$ favored path.

\section{Conclusion}

To understand the mechanism of entropy-enthalpy compensation in drug interaction with HIV-1 PR, we performed ITC experiments and NMR for four PRs at protein concentrations similar to 
each other. Observed differences in the direct and competitive titration heat flow cannot be explained without assuming an inhibitor-bound intermediate in pWT and Flap+(154A). Inhibitor interactions of these proteins involve significant conformational changes. Based on our observations, we propose two inhibitor-binding pathways, one without (entropy favorable) and the other with large conformational changes (enthalpy favorable), which may explain entropyenthalpy compensation detected in the competitive ITC experiments.

\section{Materials and Methods}

\section{Protease Expression and Purification}

HIV-1 PR with the following amino acid sequence, PQITLWKRPL VTIRIGGQLK EALLDTGADD TVIEEMNLPG KWKPKMIGGI GGFIKVRQYD QIPIEIAGHK AIGTVLVGPT PVNIIGRNLL TQIGATLNF, was used in this study. Note, the construct contains four mutations (Q7K, L33I, C67A, C95A) to reduce autoproteolysis and disulfide-bridge formation $[57 ; 58]$ and L63P polymorphism [31;62]. This sequence is called pWT in this study, to distinguish it from WT. Flap+(154) $_{(15)}$ contains mutations L10I/G48V/V82A on the pWT construct (DNA2.0, Newark, CA).

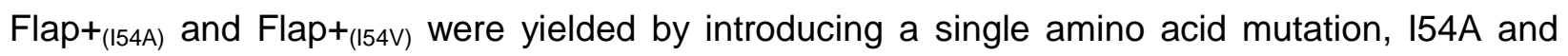
I54V, respectively, to Flap+(154). The clones were confirmed by DNA sequencing. We expressed

${ }^{15} \mathrm{~N}$ isotope labeled proteins and purified using the protocols published previously [60]. Proteins were folded with $10 \mathrm{mM}$ acetate at $\mathrm{pH} 6.0$, buffer exchanged to a $20 \mathrm{mM}$ sodium phosphate at $\mathrm{pH}$ 5.8, and concentrated approximately to 5 or $50 \mu \mathrm{M}$ (assuming a dimer). As described below, the protein concentration was re-adjusted in individual experiments. Molecular mass of the proteins used for NMR experiments were checked by Bruker QqTOF mass spectrometer. Darunavir was obtained from Celia Schiffer's group [62]. All protein concentrations in the manuscript are described by assuming the dimer unless otherwise stated. 


\section{Isothermal Titration Calorimetry}

Thermodynamics parameters of interaction of pepstatin (Sigma Aldrich, St. Louis, MO) with PR pWT, Flap+(154A), Flap+(154), and Flap+$_{{ }_{(154 V)}}$ were determined at $20{ }^{\circ} \mathrm{C}$, by conducting ITC experiments using MicroCal PEAQ-ITC calorimeter (Malvern, Westborough, MA). Buffer of the proteins was exchanged to $20 \mathrm{mM}$ phosphate at $\mathrm{pH} 5.8$ using a pre-equilibrated dialysis cassette (Thermo Fisher Sci., Waltham, MA), with the final protein concentration at $20-30 \mu \mathrm{M}$, and added $2 \%$ DMSO. The dialysis buffer was used to adjust acetyl-pepstatin concentration from $50 \mathrm{mM}$ stock in DMSO solution to $1 \mathrm{mM}$ first, making $2 \%$ DMSO condition, and next adjusted $0.3-0.6 \mathrm{mM}$ depending on the protein concentration. DRV titration was conducted in a competitive mode, i.e., in protein solution containing the 10 -fold pepstatin, $250-350 \mu \mathrm{M}$ DRV prepared from $50 \mathrm{mM}$ stock DRV solution. For comparison purposes, we used pepstatin for all the competitive experiment. For Flap+(154A), direct DRV titration was also performed to examine the heat flow. In all the experiments, the raw ITC data, after normalizing a constant control heat to zero, and the integrated heat per moles of injected inhibitors, assuming a 1:1 binding model, were plotted. Thermodynamics parameters of PR (dimer) - inhibitor interaction were determined using the Analysis software (Malvern, Westborough, MA).

\section{Fluorescence spectroscopy}

The PR concentration dependence of WT, Flap+(154A), Flap+(154) ${ }_{(15)}$ and $\mathrm{Flap}_{(154 \mathrm{~V})}$ was examined by recording intrinsic tryptophan fluorescence emission on a FluoroMax-4 spectrofluoremeter (Horiba Scientific, Edison, NJ). Proteins, taken from a $-80^{\circ} \mathrm{C}$ frozen stock, were diluted, firstly to $4 \mu \mathrm{M}$ and then step-wise dilutions to record fluorescence emission spectra with an excitation wavelength at $280 \mathrm{~nm}$ at room temperature. Emission intensity changes at $350 \mathrm{~nm}$ per molar concentration were plotted to compare the structural changes at different protein concentrations. Chemical denaturation of $1 \mu \mathrm{M}$ pWT, Flap+(154A), Flap+(154) and $\mathrm{Flap}_{{ }_{(154 \mathrm{~V})}}$ was monitored by 
recording the Trp emission at $350 \mathrm{~nm}$ at different urea (Sigma Aldrich, St. Louis, MO) concentrations in a $20 \mathrm{mM}$ phosphate buffer at $\mathrm{pH} 5.8$ at room temperature. Fluorescence data of the proteins were compared by normalizing the maximum emission at zero urea concentration among all four PRs to 1.0. Note, since the proteases are enzymatically active, each set of experiments was done within 1 hour.

\section{NMR spectroscopy}

All NMR experiments were performed for proteins in $20 \mathrm{mM}$ phosphate buffer at pH 5.8 and 20 ${ }^{\circ} \mathrm{C}$, recorded either on Bruker Avance spectrometers at either $800 \mathrm{MHz}$ or $900 \mathrm{MHz}$, and processed by nmrPipe and ccpNMR $[63 ; 64] .{ }^{1} \mathrm{H}^{-15} \mathrm{~N}$ HSQC spectra were recorded for pWT,

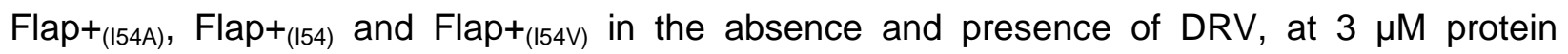
concentration (as a dimer). An additional three sets of ${ }^{1} \mathrm{H}-{ }^{15} \mathrm{~N}$ HSQC spectra were recorded for

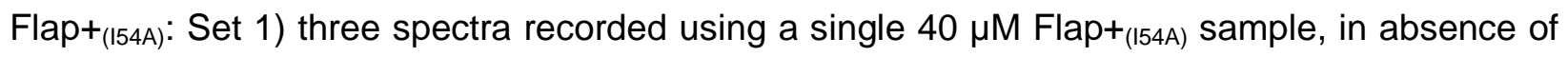
inhibitor, after addition of excess pepstatin, and after adding DRV to the pepstatin-sample, in order to understand the competitive ITC data; Set 2) two spectra recorded using a single $20 \mu \mathrm{M}$ Flap+(154A) sample first in the apo form, then after adding excess DRV, to compare with the direct DRV titration experiment; Set 3) two spectra recorded using a single $40 \mu \mathrm{M}$ Flap+(154A) protein folded in the presence of an excess amount of pepstatin, and next by adding an excess amount of DRV, to confirm the inhibitor replacement. Inhibitors added for the NMR experiments were 4 - 10 fold excess relative to each protein concentration. Each NMR experiment took $3-12$ hrs. Fractions of the unfolded component of Flap+(154A) in experimental sets, (1) - (3), were assessed from Trp indole resonance volume or height. 


\section{Acknowledgements}

We thank Teresa Brosenitsch for critical reading of the manuscript, Michael Delk for NMR support, Akbar Ali for providing the inhibitors, and Andrew C. Hinck for sharing the ITC instrument of his group for the initial experiments. This study was supported by grants from the National Institutes of Health (P01 GM109767 and S10OD023481).

\section{Supporting Information.}

A pdf file that contains the following data is available free of charge: Figure S1, NMR spectra

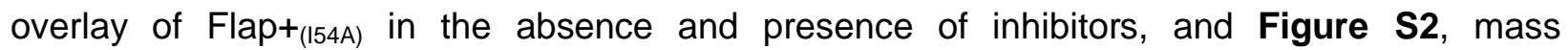
spectrometry data of the PR and Flap+ mutants.

\section{ORCID.}

Rieko Ishima - 0000-0002-3418-0922

Masayuki Oda - 0000-0002-8568-4223

John D. Persons - 0000-0002-0663-3330 
Table 1. Thermodynamics parameters obtained from calorimetric titration of PR with inhibitors: (1.1) pepstatin-binding parameters, (1.2) DRV-binding parameters in the presence of excess amount of pepstatin, and (1.3) DRV-binding parameters extracted from (1.1) and (1.2).

Table 1.1 Pepstatin titration

\begin{tabular}{|c|c|c|c|c|c|c|c|c|c|}
\hline & & \multicolumn{2}{|l|}{ WT } & \multicolumn{2}{|c|}{ Flap(I54A) } & \multicolumn{2}{|l|}{ Flap(I54) } & \multicolumn{2}{|c|}{ Flap(I54V) } \\
\hline & & value & error & value & error & value & error & value & error \\
\hline $\mathrm{K}_{\mathrm{D}}$ & nano-M & 315 & 75 & 218 & 29 & 814 & 87 & 819 & 55 \\
\hline$\Delta \mathrm{G}$ & $\mathrm{kcal} / \mathrm{mol}$ & -8.72 & 0.14 & -8.94 & 0.078 & -8.17 & 0.062 & -8.01 & 0.039 \\
\hline$\Delta \mathrm{H}$ & $\mathrm{kcal} / \mathrm{mol}$ & 8.67 & 0.24 & 7.58 & 0.10 & 13.5 & 0.21 & 16.6 & 0.14 \\
\hline$-\mathrm{T} \Delta \mathrm{S}$ & $\mathrm{kcal} / \mathrm{mol}$ & -17.4 & 0.28 & -16.5 & 0.13 & -21.6 & 0.22 & -24.8 & 0.15 \\
\hline $\mathrm{N}$ & & 0.905 & 0.013 & 0.728 & 0.0052 & 1.03 & 0.0039 & 1.14 & 0.0056 \\
\hline
\end{tabular}

Table 1.2 DRV titration in the presence of pepstatin

\begin{tabular}{|c|c|c|c|c|c|c|c|c|c|}
\hline & & \multicolumn{2}{|l|}{ WT } & \multicolumn{2}{|c|}{ Flap(I54A) } & \multicolumn{2}{|l|}{ Flap(I54) } & \multicolumn{2}{|c|}{ Flap(I54V) } \\
\hline & & value & error & value & error & value & error & value & error \\
\hline$K_{D}$ & nano-M & 23 & 8.4 & 47.2 & 8.3 & 19.1 & 15 & 27 & 12 \\
\hline$\Delta \mathrm{G}$ & $\mathrm{kcal} / \mathrm{mol}$ & -10.2 & 0.21 & -9.83 & 0.10 & -10.6 & 0.46 & -10.4 & 0.26 \\
\hline$\Delta \mathrm{H}$ & $\mathrm{kcal} / \mathrm{mol}$ & -17.9 & 0.30 & -13.7 & 0.16 & -15.2 & 0.47 & -15.4 & 0.29 \\
\hline$-\mathrm{T} \Delta \mathrm{S}$ & $\mathrm{kcal} / \mathrm{mol}$ & 7.61 & 0.37 & 3.89 & 0.19 & 4.64 & 0.66 & 4.95 & 0.39 \\
\hline \multicolumn{2}{|l|}{$\mathrm{N}$} & 1.15 & 0.0067 & 0.757 & 0.0037 & 1.41 & 0.013 & 1.38 & 0.01 \\
\hline & & \multicolumn{2}{|l|}{ WT } & \multicolumn{2}{|c|}{ Flap(I54A) } & \multicolumn{2}{|l|}{ Flap(I54) } & \multicolumn{2}{|c|}{ Flap(I54V) } \\
\hline & & value & error & value & error & value & error & value & error \\
\hline$K_{D}$ & pico-M & 33.3 & 12 & 58 & 24 & 88 & 70 & 113 & 48 \\
\hline$\Delta \mathrm{G}$ & $\mathrm{kcal} / \mathrm{mol}$ & -14.1 & 0.22 & -13.7 & 0.24 & -13.8 & 0.46 & -13.6 & 0.25 \\
\hline$\Delta \mathrm{H}$ & $\mathrm{kcal} / \mathrm{mol}$ & -9.37 & 0.30 & -6.4 & 0.41 & -1.91 & 0.48 & 1.1 & 0.29 \\
\hline$-\mathrm{T} \Delta \mathrm{S}$ & $\mathrm{kcal} / \mathrm{mol}$ & -4.69 & 0.37 & -7.34 & 0.48 & -11.2 & 0.67 & -14.7 & 0.38 \\
\hline
\end{tabular}


Table 2. Unfolded fractions in Flap+(I54A) estimated from Trp indole NMR peak intensity.

\begin{tabular}{|c|c|c|c|c|c|c|c|}
\hline \multirow[t]{2}{*}{$\begin{array}{l}\text { Unfolded } \\
\text { fraction }\end{array}$} & \multicolumn{3}{|c|}{$\begin{array}{l}\text { Sequential inhibitor addition } \\
\text { (Competitive-ITC mimic) }\end{array}$} & \multicolumn{2}{|c|}{$\begin{array}{l}\text { Each inhibitor addition } \\
\text { (Direct-ITC mimic) }\end{array}$} & \multicolumn{2}{|c|}{$\begin{array}{l}\text { Folded in the } \\
\text { presence of pepstatin }\end{array}$} \\
\hline & apo & pepstatin & pepstatin+DRV & apo & DRV & pepstatin & DRV \\
\hline Peak volume ${ }^{a}$ & 0.22 & 0.23 & 0.20 & 0.23 & 0.24 & 0.058 & 0.055 \\
\hline Peak height ${ }^{b}$ & 0.19 & 0.19 & 0.20 & 0.20 & 0.21 & 0.081 & 0.027 \\
\hline
\end{tabular}

a estimated using the peak volumes.

${ }^{\mathrm{b}}$ estimated using the peak heights. 


\section{Figure caption}

Figure 1. PR structure, showing location of residues L10, G48 and V82 (yellow spheres), and 154 (red spheres) that are mutated in $\mathrm{Flap}_{(154 \mathrm{~V})}$ and Flap+(154A). Two subunits, A and B, are depicted in green and light blue, respectively. Flap region (residues 45-55) and the active-site fireman's grip (residues 25 to 27 ) are highlighted in pink with the residue numbers in a small font. Terminal $\beta$-sheet regions, residues from 1 to 4 and 96 to 99 , are marked in a small font. Structure was generated using PDB: 1T3R [65].

Figure 2. Calorimetric titration of HIV-1 pWT and the Flap+ mutants with (a- h) pepstatin or (i p) DRV in the presence of excess amount of pepstatin. The heat effects associated with the injection of the inhibitors (a-d and $\mathrm{i}-\mathrm{I}$ ) and corresponding isotherms (e-h and m-p) are shown.

Figure 3. Differences in thermodynamics parameters of Flap+ mutants relative to pWT: (a-c) apepstatin binding to the proteins and (d-f) DRV binding to the proteins: (a and d) Flap $+_{(154 A)}-$ pWT; (b and e) $\mathrm{Flap}_{{ }_{(154)}}-\mathrm{pWT}$; (c and f) $\mathrm{Flap}_{{ }_{(154 \mathrm{~V})}}-\mathrm{pWT}$. In each panel, $\Delta \Delta G=\Delta G_{\mathrm{Flap}_{+}}-\Delta G_{\mathrm{WT}}$, $\Delta \Delta H=\Delta H_{\text {Flap }+}-\Delta H_{\text {pWT }}$ and $\Delta(-T \Delta S)=\left(-T \Delta S_{\text {Flap }+}\right)-\left(-T \Delta S_{\text {pWT }}\right)$ are shown.

Figure 4. Comparison of heat flow signals of pWT and Flap+ mutants at (a) 7 min and (b) 12 $\min \left(3^{\text {rd }}\right.$ and $5^{\text {th }}$ injections) taken from Figures $2 i-2$, and (c) calorimetric titration of Flap ${ }_{(154 \mathrm{~A})}$ with DRV in the absence of pepstatin. In (a) and (b), heat flows of the competitive titration are shown by solid lines for pWT(blue), Flap+(154A) $($ green), Flap+(154) $($ red), and Flap+(154V) $($ purple), while that of the direct Flap+(154A) titration with DRV is shown by green dashed line. In (a) and (b), maximum heat change was normalized to $1.0 \mu \mathrm{cal} / \mathrm{s}$ to compare the heat flow changes, except for the competitive titration of Flap+(I54A). 
Figure 5. Intrinsic Trp fluorescence emission at $350 \mathrm{~nm}$ (a) at varying PR concentrations and (b) at varying urea concentrations, (c, d) overlay of ${ }^{1} \mathrm{H}-{ }^{15} \mathrm{~N}$ HSQC spectra of pWT (blue),

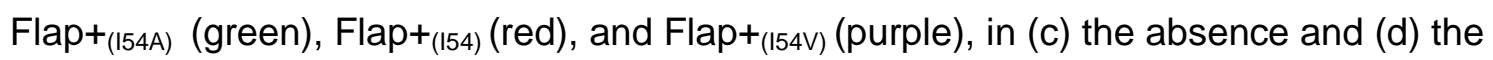
presence of DRV at $3 \mu \mathrm{M}$ protein concentrations, and $(e, f)$ overlay of ${ }^{1} \mathrm{H}-{ }^{15} \mathrm{~N} H S Q \mathrm{C}$ spectra of Flap $_{(154 \mathrm{~A})}$ recorded using a single $40 \mu \mathrm{M}$ concentration sample (e) before (black) and after (red) adding excess amount of pepstatin, and, (f) in the presence of pepstain, before (red) and after (green) adding excess amount of DRV.

Figure 6. Two models of PR interaction with inhibitors: (a) a single-pathway model and (b) a two-pathway model. Competitive inhibitor titration experiments should result in the same heat flow to that of the direct inhibitor titration in model (a) while competitive inhibitor titration experiments can result in a different heat flow from that of the direct inhibitor titration in model (b). 


\section{References}

1. Kohl, N. E., Emini, E. A., Schleif, W. A., Davis, L. J., Heimbach, J. C., Dixon, R. A., Scolnick, E. M. \& Sigal, I. S. (1988). Active human immunodeficiency virus protease is required for viral infectivity. Proc Natl Acad Sci U S A 85, 4686-4690.

2. Seelmeier, S., Schmidt, H., Turk, V. \& von der Helm, K. (1988). Human immunodeficiency virus has an aspartic-type protease that can be inhibited by pepstatin A. Proc Natl Acad Sci U S A 85, 6612-6616.

3. Oroszlan, S. \& Luftig, R. B. (1990). Retroviral proteinases. Curr Top Microbiol Immunol 157, 153-185.

4. Krausslich, H. G. (1991). Human-Immunodeficiency-Virus Proteinase Dimer as Component of the Viral Polyprotein Prevents Particle Assembly and Viral Infectivity. $P$ Natl Acad Sci USA 88, 3213-3217.

5. Kaplan, A. H., Zack, J. A., Knigge, M., Paul, D. A., Kempf, D. J., Norbeck, D. W. \& Swanstrom, R. (1993). Partial inhibition of the human immunodeficiency virus type 1 protease results in aberrant virus assembly and the formation of noninfectious particles. J Virol 67, 4050-4055.

6. Wlodawer, A. \& Erickson, J. W. (1993). Structure-based inhibitors of HIV-1 protease. Annu Rev Biochem 62, 543-585.

7. Erickson, J. W. \& Burt, S. K. (1996). Structural mechanisms of HIV drug resistance. Annu Rev Pharmacol Toxicol 36, 545-571.

8. Wlodawer, A. \& Vondrasek, J. (1998). Inhibitors of HIV-1 protease: a major success of structure-assisted drug design. Annu Rev Biophys Biomol Struct 27, 249-284.

9. Koh, Y., Nakata, H., Maeda, K., Ogata, H., Bilcer, G., Devasamudram, T., Kincaid, J. F., Boross, P., Wang, Y. F., Tie, Y., Volarath, P., Gaddis, L., Harrison, R. W., Weber, I. T., Ghosh, A. K. \& Mitsuya, H. (2003). Novel bis-tetrahydrofuranylurethane-containing nonpeptidic protease inhibitor (PI) UIC-94017 (TMC114) with potent activity against multi-PI-resistant human immunodeficiency virus in vitro. Antimicrob Agents Chemother 47, 3123-3129.

10. Surleraux, D. L., de Kock, H. A., Verschueren, W. G., Pille, G. M., Maes, L. J., Peeters, A., Vendeville, S., De Meyer, S., Azijn, H., Pauwels, R., de Bethune, M. P., King, N. M., Prabu-Jeyabalan, M., Schiffer, C. A. \& Wigerinck, P. B. (2005). Design of HIV-1 protease inhibitors active on multidrug-resistant virus. J Med Chem 48, 1965-1973.

11. Altman, M. D., Ali, A., Reddy, G. S., Nalam, M. N., Anjum, S. G., Cao, H., Chellappan, S., Kairys, V., Fernandes, M. X., Gilson, M. K., Schiffer, C. A., Rana, T. M. \& Tidor, B. (2008). HIV-1 protease inhibitors from inverse design in the substrate envelope exhibit subnanomolar binding to drug-resistant variants. J Am Chem Soc 130, 6099-6113.

12. Quinones-Mateu, M. E., Moore-Dudley, D. M., Jegede, O., Weber, J. \& E, J. A. (2008). Viral drug resistance and fitness. Adv Pharmacol 56, 257-296.

13. Ghosh, A. K., Chapsal, B. D., Weber, I. T. \& Mitsuya, H. (2008). Design of HIV protease inhibitors targeting protein backbone: an effective strategy for combating drug resistance. Acc Chem Res 41, 78-86.

14. Nalam, M. N. \& Schiffer, C. A. (2008). New approaches to HIV protease inhibitor drug design II: testing the substrate envelope hypothesis to avoid drug resistance and discover robust inhibitors. Curr Opin HIV AIDS 3, 642-646.

15. Galiano, L., Ding, F., Veloro, A. M., Blackburn, M. E., Simmerling, C. \& Fanucci, G. E. (2009). Drug pressure selected mutations in HIV-1 protease alter flap conformations. J Am Chem Soc 131, 430-431. 
16. Weber, I. T. \& Agniswamy, J. (2009). HIV-1 Protease: Structural Perspectives on Drug Resistance. Viruses 1, 1110-1136.

17. Van Marck, H., Dierynck, I., Kraus, G., Hallenberger, S., Pattery, T., Muyldermans, G., Geeraert, L., Borozdina, L., Bonesteel, R., Aston, C., Shaw, E., Chen, Q., Martinez, C., Koka, V., Lee, J., Chi, E., de Bethune, M. P. \& Hertogs, K. (2009). The impact of individual human immunodeficiency virus type 1 protease mutations on drug susceptibility is highly influenced by complex interactions with the background protease sequence. J Virol 83, 9512-9520.

18. Koh, Y., Amano, M., Towata, T., Danish, M., Leshchenko-Yashchuk, S., Das, D., Nakayama, M., Tojo, Y., Ghosh, A. K. \& Mitsuya, H. (2010). In vitro selection of highly darunavir-resistant and replication-competent HIV-1 variants by using a mixture of clinical HIV-1 isolates resistant to multiple conventional protease inhibitors. J Virol 84, 11961-11969.

19. Nalam, M. N., Ali, A., Altman, M. D., Reddy, G. S., Chellappan, S., Kairys, V., Ozen, A., Cao, H., Gilson, M. K., Tidor, B., Rana, T. M. \& Schiffer, C. A. (2010). Evaluating the substrate-envelope hypothesis: structural analysis of novel HIV-1 protease inhibitors designed to be robust against drug resistance. J Virol 84, 5368-5378.

20. Ghosh, A. K., Yu, X., Osswald, H. L., Agniswamy, J., Wang, Y. F., Amano, M., Weber, I. T. \& Mitsuya, H. (2015). Structure-based design of potent HIV-1 protease inhibitors with modified P1-biphenyl ligands: synthesis, biological evaluation, and enzyme-inhibitor Xray structural studies. J Med Chem 58, 5334-5343.

21. Luque, I., Todd, M. J., Gomez, J., Semo, N. \& Freire, E. (1998). Molecular basis of resistance to HIV-1 protease inhibition: a plausible hypothesis. Biochemistry $37,5791-$ 5797.

22. Todd, M. J., Semo, N. \& Freire, E. (1998). The structural stability of the HIV-1 protease. $\mathrm{J}$ Mol Biol 283, 475-488.

23. Velazquez-Campoy, A., Todd, M. J. \& Freire, E. (2000). HIV-1 Protease Inhibitors: Enthalpic versus Entropic Optimization of the Binding Affinity†. Biochemistry 39, 2201-2207.

24. Velazquez-Campoy, A., Todd, M. J., Vega, S. \& Freire, E. (2001). Catalytic efficiency and vitality of HIV-1 proteases from African viral subtypes. Proc Natl Acad Sci U S A 98, 6062-6067.

25. Prabu-Jeyabalan, M., Nalivaika, E. \& Schiffer, C. A. (2002). Substrate shape determines specificity of recognition for HIV-1 protease: analysis of crystal structures of six substrate complexes. Structure 10, 369-381.

26. Velazquez-Campoy, A., Muzammil, S., Ohtaka, H., Schon, A., Vega, S. \& Freire, E. (2003). Structural and thermodynamic basis of resistance to HIV-1 protease inhibition: implications for inhibitor design. Curr Drug Targets Infect Disord 3, 311-328.

27. Vega, S., Kang, L. W., Velazquez-Campoy, A., Kiso, Y., Amzel, L. M. \& Freire, E. (2004). A structural and thermodynamic escape mechanism from a drug resistant mutation of the HIV-1 protease. Proteins 55, 594-602.

28. King, N. M., Prabu-Jeyabalan, M., Nalivaika, E. A. \& Schiffer, C. A. (2004). Combating susceptibility to drug resistance: lessons from HIV-1 protease. Chem Biol 11, 13331338.

29. Ohtaka, H. \& Freire, E. (2005). Adaptive inhibitors of the HIV-1 protease. Prog Biophys Mol Biol 88, 193-208.

30. Foulkes, J. E., Prabu-Jeyabalan, M., Cooper, D., Henderson, G. J., Harris, J., Swanstrom, R. \& Schiffer, C. A. (2006). Role of invariant Thr80 in human immunodeficiency virus type 1 protease structure, function, and viral infectivity. J Virol 80, 6906-6916. 
31. King, N. M., Prabu-Jeyabalan, M., Bandaranayake, R. M., Nalam, M. N., Nalivaika, E. A., Ozen, A., Haliloglu, T., Yilmaz, N. K. \& Schiffer, C. A. (2012). Extreme entropy-enthalpy compensation in a drug-resistant variant of HIV-1 protease. ACS Chem Biol 7, 15361546.

32. Foulkes-Murzycki, J. E., Rosi, C., Kurt Yilmaz, N., Shafer, R. W. \& Schiffer, C. A. (2013). Cooperative effects of drug-resistance mutations in the flap region of HIV-1 protease. ACS Chem Biol 8, 513-518.

33. Ragland, D. A., Nalivaika, E. A., Nalam, M. N., Prachanronarong, K. L., Cao, H., Bandaranayake, R. M., Cai, Y., Kurt-Yilmaz, N. \& Schiffer, C. A. (2014). Drug resistance conferred by mutations outside the active site through alterations in the dynamic and structural ensemble of HIV-1 protease. J Am Chem Soc 136, 11956-11963.

34. Ohtaka, H., Schon, A. \& Freire, E. (2003). Multidrug resistance to HIV-1 protease inhibition requires cooperative coupling between distal mutations. Biochemistry 42 , 13659-13666.

35. Pearl, L. \& Blundell, T. (1984). The active site of aspartic proteinases. FEBS Lett 174, 96-101.

36. Pearl, L. H. \& Taylor, W. R. (1987). A structural model for the retroviral proteases. Nature 329, 351-354.

37. Wlodawer, A., Miller, M., Jaskolski, M., Sathyanarayana, B. K., Baldwin, E., Weber, I. T., Selk, L. M., Clawson, L., Schneider, J. \& Kent, S. B. (1989). Conserved folding in retroviral proteases: crystal structure of a synthetic HIV-1 protease. Science 245, 616621.

38. Collins, J. R., Burt, S. K. \& Erickson, J. W. (1995). Flap Opening in Hiv-1 Protease Simulated by Activated Molecular-Dynamics. Nature Structural Biology 2, 334-338.

39. Nicholson, L. K., Yamazaki, T., Torchia, D. A., Grzesiek, S., Bax, A., Stahl, S. J., Kaufman, J. D., Wingfield, P. T., Lam, P. Y., Jadhav, P. K. \& et al. (1995). Flexibility and function in HIV-1 protease. Nat Struct Biol 2, 274-280.

40. Ishima, R., Freedberg, D. I., Wang, Y. X., Louis, J. M. \& Torchia, D. A. (1999). Flap opening and dimer-interface flexibility in the free and inhibitor-bound HIV protease, and their implications for function. Structure 7, 1047-1055.

41. Freedberg, D. I., Ishima, R., Jacob, J., Wang, Y. X., Kustanovich, I., Louis, J. M. \& Torchia, D. A. (2002). Rapid structural fluctuations of the free HIV protease flaps in solution: relationship to crystal structures and comparison with predictions of dynamics calculations. Protein Sci 11, 221-232.

42. Perryman, A. L., Lin, J. H. \& McCammon, J. A. (2004). HIV-1 protease molecular dynamics of a wild-type and of the V82F/I84V mutant: possible contributions to drug resistance and a potential new target site for drugs. Protein Sci 13, 1108-1123.

43. Meagher, K. L. \& Carlson, H. A. (2005). Solvation influences flap collapse in HIV-1 protease. PROTEINS-STRUCTURE FUNCTION AND BIOINFORMATICS 58, 119-125.

44. Hornak, V., Okur, A., Rizzo, R. C. \& Simmerling, C. (2006). HIV-1 protease flaps spontaneously open and reclose in molecular dynamics simulations. P Natl Acad Sci USA 103, 915-920.

45. Ishima, R. \& Louis, J. M. (2008). A diverse view of protein dynamics from NMR studies of HIV-1 protease flaps. Proteins 70, 1408-1415.

46. Cai, Y., Yilmaz, N. K., Myint, W., Ishima, R. \& Schiffer, C. A. (2012). Differential Flap Dynamics in Wild-type and a Drug Resistant Variant of HIV-1 Protease Revealed by Molecular Dynamics and NMR Relaxation. J Chem Theory Comput 8, 3452-3462.

47. Cai, Y., Myint, W., Paulsen, J. L., Schiffer, C. A., Ishima, R. \& Kurt Yilmaz, N. (2014). Drug Resistance Mutations Alter Dynamics of Inhibitor-Bound HIV-1 Protease. J Chem Theory Comput 10, 3438-3448. 
48. Noel, A. F., Bilsel, O., Kundu, A., Wu, Y., Zitzewitz, J. A. \& Matthews, C. R. (2009). The folding free-energy surface of HIV-1 protease: insights into the thermodynamic basis for resistance to inhibitors. J Mol Biol 387, 1002-1016.

49. Pietrucci, F., Vargiu, A. V. \& Kranjc, A. (2015). HIV-1 Protease Dimerization Dynamics Reveals a Transient Druggable Binding Pocket at the Interface. Sci Rep 5, 18555.

50. Koh, Y., Aoki, M., Danish, M. L., Aoki-Ogata, H., Amano, M., Das, D., Shafer, R. W., Ghosh, A. K. \& Mitsuya, H. (2011). Loss of protease dimerization inhibition activity of darunavir is associated with the acquisition of resistance to darunavir by HIV-1. J Virol 85, 10079-10089.

51. Hayashi, H., Takamune, N., Nirasawa, T., Aoki, M., Morishita, Y., Das, D., Koh, Y., Ghosh, A. K., Misumi, S. \& Mitsuya, H. (2014). Dimerization of HIV-1 protease occurs through two steps relating to the mechanism of protease dimerization inhibition by darunavir. Proc Natl Acad Sci U S A 111, 12234-12239.

52. Kovacs, H., Moskau, D. \& Spraul, M. (2005). Cryogenically cooled probes - a leap in NMR technology. Progress in Nuclear Magnetic Resonance Spectroscopy 46, 131-155.

53. Ohtaka, H., Velazquez-Campoy, A., Xie, D. \& Freire, E. (2002). Overcoming drug resistance in HIV-1 chemotherapy: the binding thermodynamics of Amprenavir and TMC-126 to wild-type and drug-resistant mutants of the HIV-1 protease. Protein Sci 11, 1908-1916.

54. Lafont, V., Armstrong, A. A., Ohtaka, H., Kiso, Y., Mario Amzel, L. \& Freire, E. (2007). Compensating enthalpic and entropic changes hinder binding affinity optimization. Chem Biol Drug Des 69, 413-422.

55. Tomasselli, A. G., Olsen, M. K., Hui, J. O., Staples, D. J., Sawyer, T. K., Heinrikson, R. L. \& Tomich, C. S. C. (2002). Substrate analog inhibition and active site titration of purified recombinant HIV-1 protease. Biochemistry 29, 264-269.

56. Sigurskjold, B. W. (2000). Exact analysis of competition ligand binding by displacement isothermal titration calorimetry. Anal Biochem 277, 260-266.

57. Ishima, R., Ghirlando, R., Tozser, J., Gronenborn, A. M., Torchia, D. A. \& Louis, J. M. (2001). Folded monomer of HIV-1 protease. J Biol Chem 276, 49110-49116.

58. Ishima, R., Torchia, D. A., Lynch, S. M., Gronenborn, A. M. \& Louis, J. M. (2003). Solution structure of the mature HIV-1 protease monomer: insight into the tertiary fold and stability of a precursor. J Biol Chem 278, 43311-43319.

59. Louis, J. M., Deshmukh, L., Sayer, J. M., Aniana, A. \& Clore, G. M. (2015). Mutations Proximal to Sites of Autoproteolysis and the alpha-Helix That Co-evolve under Drug Pressure Modulate the Autoprocessing and Vitality of HIV-1 Protease. Biochemistry 54, 5414-5424.

60. Khan, S. N., Persons, J. D., Paulson, J. L., Guerrero, M., Schiffer, C. A., Kurt-Yilmaz, N. \& Ishima, R. (2018). Probing Structural Changes among Analogous Inhibitor-Bound Forms of HIV-1 Protease and a Drug-Resistant Mutant in Solution by NMR. Biochemistry.

61. Côté, H. C., Brumme, Z. L. \& Harrigan, P. R. (2001). Human immunodeficiency virus type 1 protease cleavage site mutations associated with protease inhibitor crossresistance selected by indinavir, ritonavir, and/or saquinavir. J Virol 75, 589-594.

62. Nalam, M. N., Ali, A., Reddy, G. S., Cao, H., Anjum, S. G., Altman, M. D., Yilmaz, N. K., Tidor, B., Rana, T. M. \& Schiffer, C. A. (2013). Substrate envelope-designed potent HIV1 protease inhibitors to avoid drug resistance. Chem Biol 20, 1116-1124.

63. Delaglio, F., Grzesiek, S., Vuister, G. W., Zhu, G., Pfeifer, J. \& Bax, A. (1995). NMRPipe: a multidimensional spectral processing system based on UNIX pipes. J Biomol NMR 6, 277-293. 
64. Vranken, W. F., Boucher, W., Stevens, T. J., Fogh, R. H., Pajon, A., Llinas, M., Ulrich, E. L., Markley, J. L., Ionides, J. \& Laue, E. D. (2005). The CCPN data model for NMR spectroscopy: development of a software pipeline. Proteins 59, 687-696.

65. Surleraux, D. L., Tahri, A., Verschueren, W. G., Pille, G. M., de Kock, H. A., Jonckers, T. H., Peeters, A., De Meyer, S., Azijn, H., Pauwels, R., de Bethune, M. P., King, N. M., Prabu-Jeyabalan, M., Schiffer, C. A. \& Wigerinck, P. B. (2005). Discovery and selection of TMC114, a next generation HIV-1 protease inhibitor. J Med Chem 48, 1813-1822. 
Figure 1.

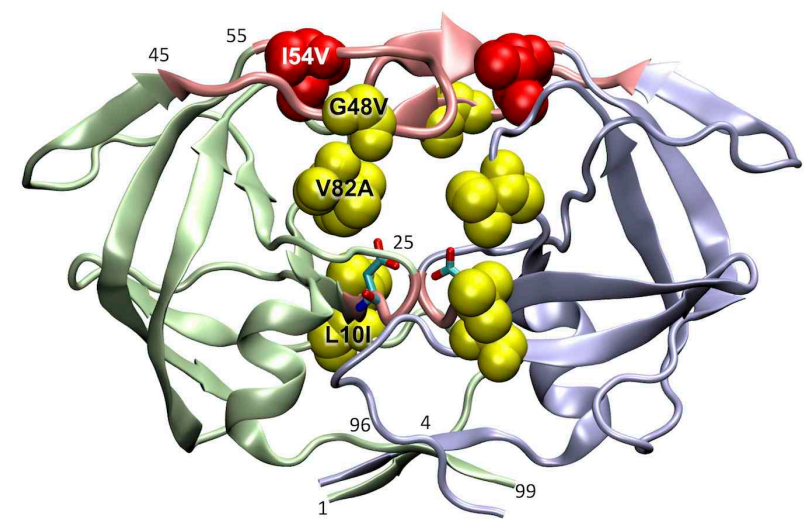

Figure 2.

Acetyl-pepstatin titration to $P R$
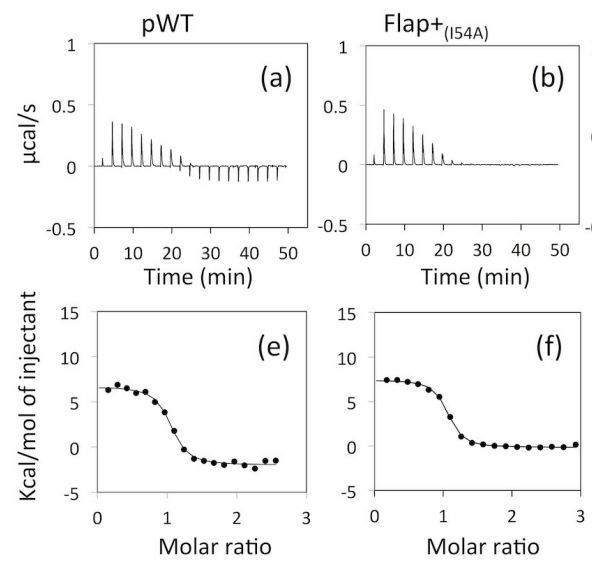

(b)
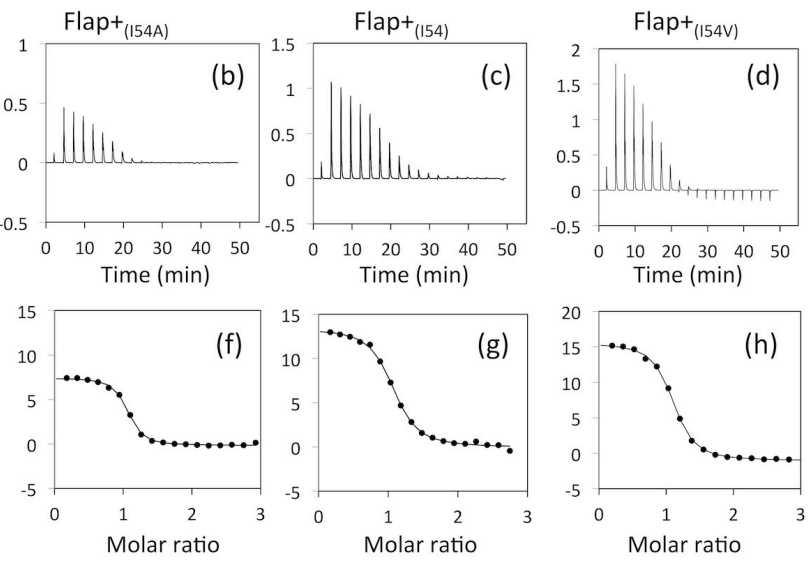

\section{$D R V$ titration to $P R$ in the presence of acetyl-pepstatin}
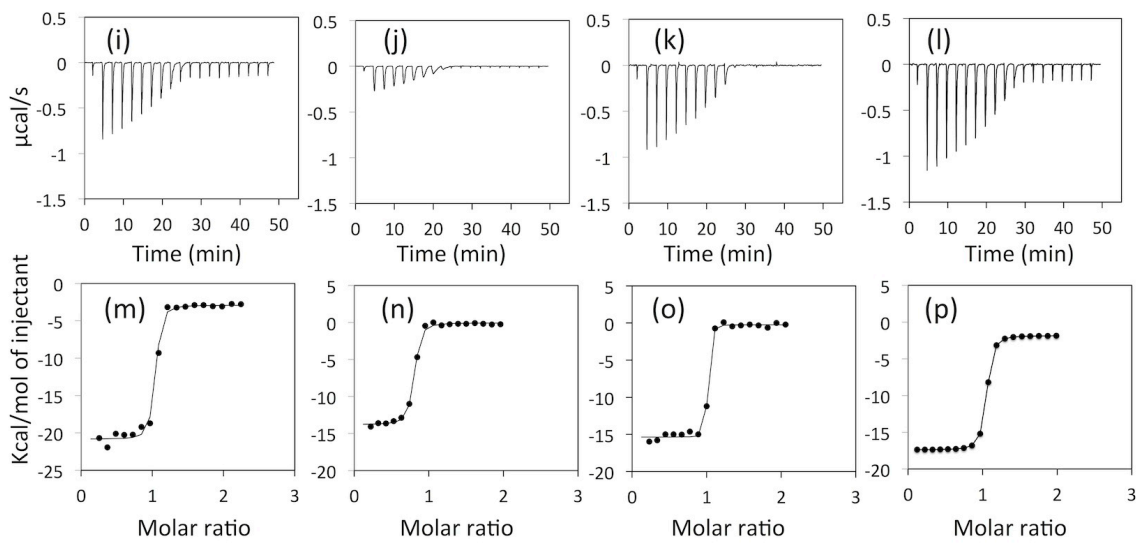
Figure 3.

\section{Acetyl-pepstatin titration to $P R$}

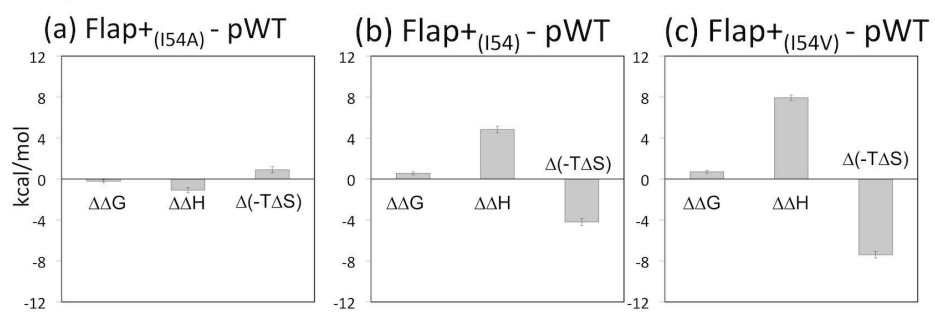

DRV titration to $P R$

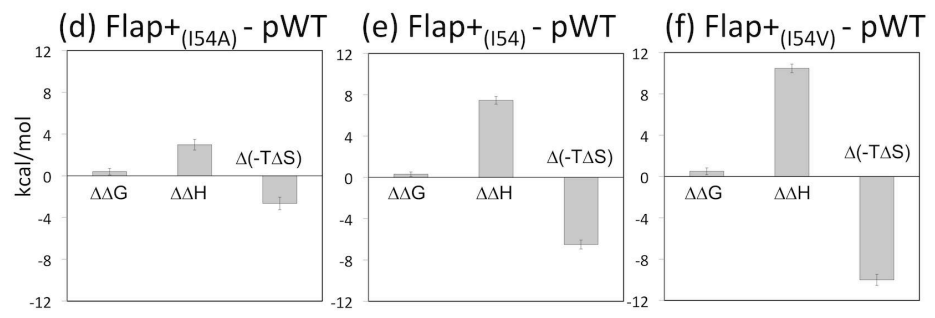

Figure 4.
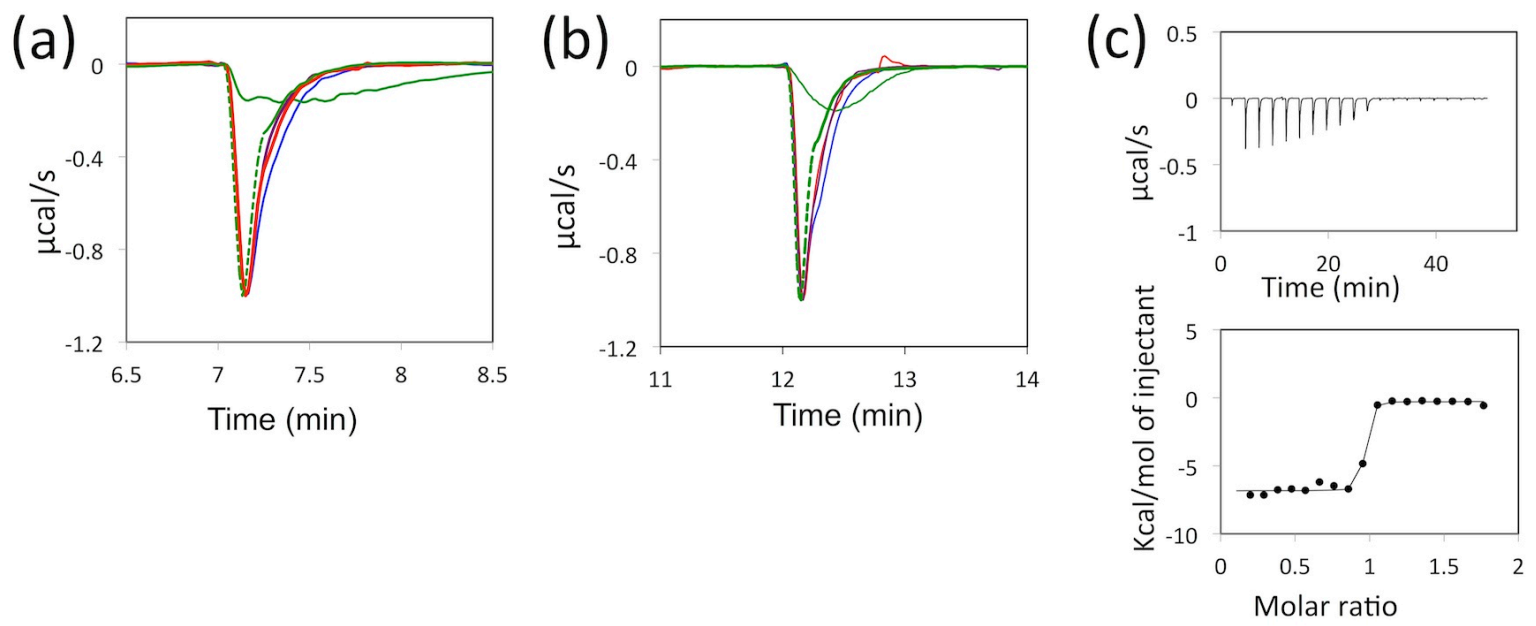
Figure 5.

(a) Trp-fluorescence

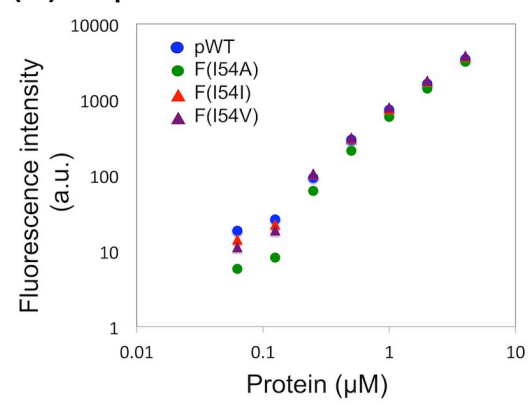

(c) Apo forms at $3 \mu \mathrm{M}$

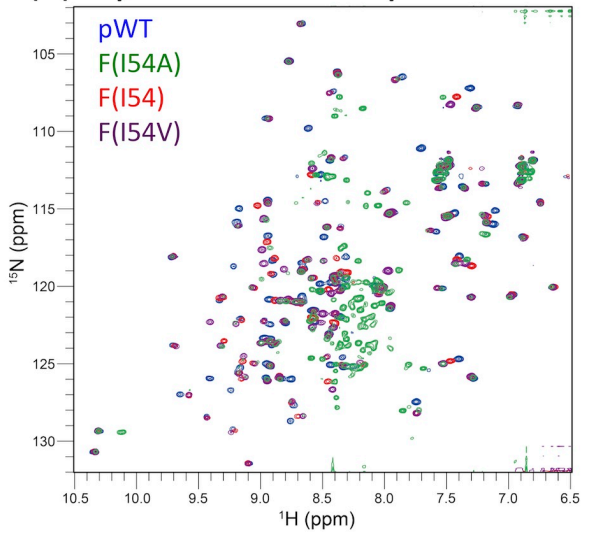

(b) Trp-fluorescence

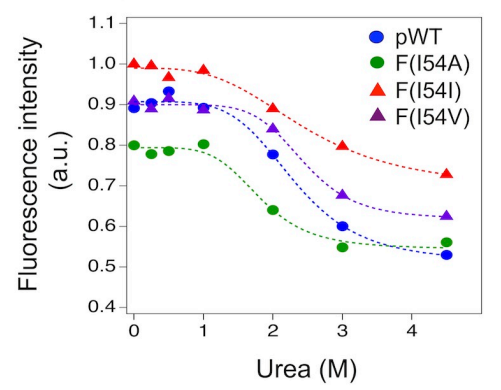

(d) DRV bound forms at $3 \mu \mathrm{M}$

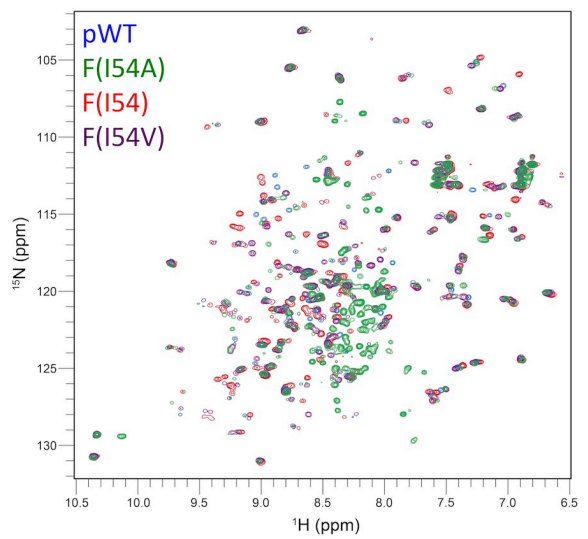

(e) Apo v.s. pepstatin at $40 \mu \mathrm{M}$
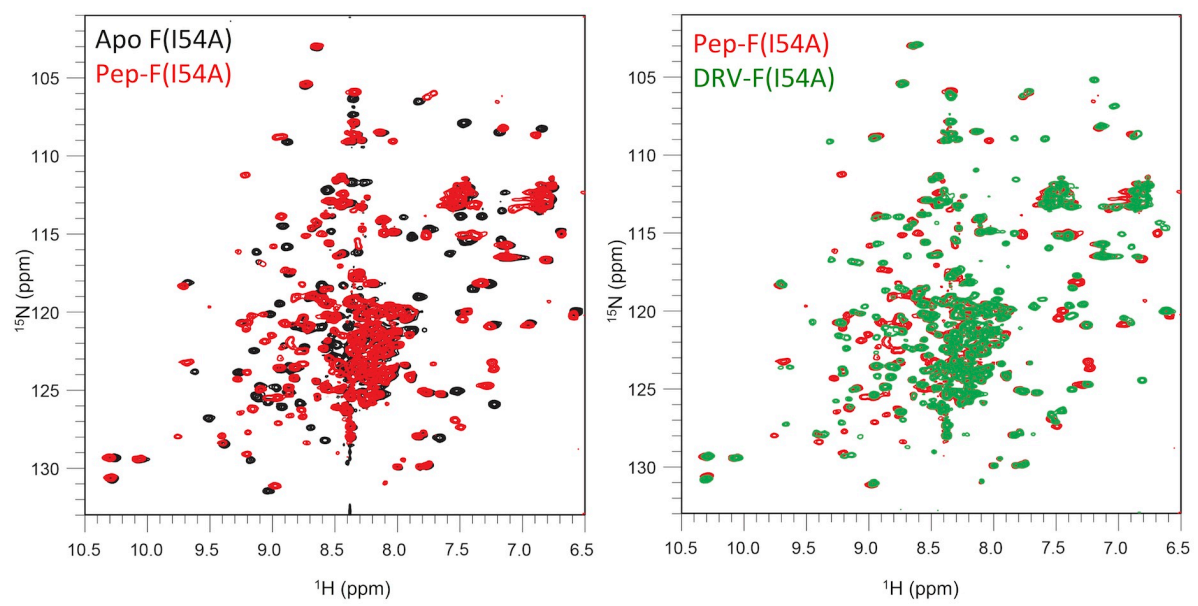
Figure 6.

(a) A single-pathway model

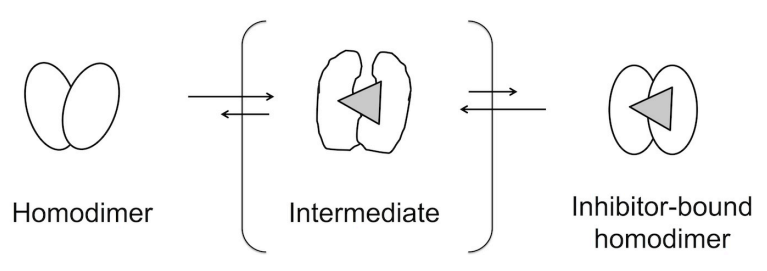

(b) A two-pathway model

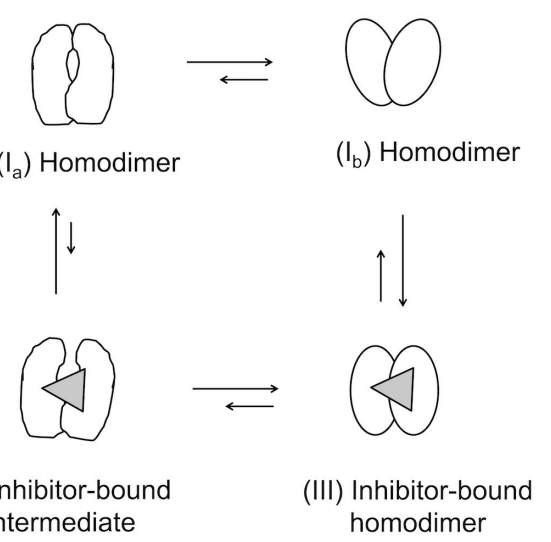

